Somers-town, to the assistance of a child, about eighteen or twenty months old, who, I was told, had been suddenly seized with a "fit." It was lyiug in its mother's lap, apparently dying. The surface of the body was cold, and covered with a clammy perspiration, and the countenance injected and livid; the pupils were dilated, the eyes fixed, and the eyelids partially closed; the mouth contained a quantity of frothy saliva; the respiration was hurried and oppressed; and the pulse rapid and feeble. The parents of the child, and two or three other persons who were present on my arrival, felt so assured of its immediate death, that I was requested not to interfere in any way. I had much difficulty to induce the parents to forego their resolution. Having only two or three days previously lost a child under very similar circumstances, at Camden-town, I became immediately resolved on a different kind of treatment to that I had then adopted; that is, I chose to open a branch of the temporal artery ratber than wait the issue of a modified procedure. I abstracted very little short of a wineglassful of blood, and then, having desired the father to press the bleeding orifice with the point of his finger, I quickly administered, by means of a tea spoon inserted into the pharynx, a little brandy and water. The excellent effects of the treatment became immediately apparent. I was no less surprised than those about me. The surface of the body became warm, the respiration natural, and the pulse normal. My little patient was presently conscious, though much disposed to sleep. I called after four or five hours and found the child very comfortable and perfectly rational. I directed a purgative to be given. The next morning it was brought to my residence in Clarendon-square, perfectly well.

'The above case, Mr. Editor, I consider highly interesting. I make no doubt that the more general practice of using leeches in cases of the kind may be, in many cases, very properly substituted by general bleeding. If children are but men in miniature, wherefore should we not treat them as such? Moralists do so, and why not doctors?

In the adult, an assemblage of symptoms like to those described by Mr. Adams, would, in the minds of most medical men, constitute an attack of congestive or serous apoplexy, and particularly so when regarded in connection with the appearances observed after death. I have the notes of three such cases by me, the particulars of which, both before and after death, strongly confirm me in my opinion. The general sinking of the vital powers, which so commonly characterises sudden attacks of this nature, being, as a matter of course, dependant on a very different cause to that which obtains in the last stages of chronic hydrocephalus, and from which it may be said to differ only in degree, we are not disposed to agree with
Mr. Adams when he says that "the affec" tion is invariably fatal," or that "the treatment indicated can only be palliative, and adopted to prevent impressions that nothing has been done or attempted for the patient."

I think it at any rate possible that had Mr. Adams's little patient lost from half an ounce to one ounce of blood immediately on that gentleman's arrival, its life might have been saved. I am, Sir, your obedient servant,

James George Davey, M.D., Lon.

Hanwell Asylum, Middlesex, April 6, 1843 .

\section{CANCRUM ORIS, NOT A RESULT OF MERCURY. ANALOGOUS AFFECTION.}

To the Editor of THE LANCET.

Srr, - The discussion on gangrene of the face, or cancrum oris, which took place at the last meeting of the Royal Medico-Chirurgical Society (p. 61) merits the best attention of your reader's. The remarks of Dr. Marshall Hall upon the non-production of the disease by mercury are especially important; and if those of your correspondents who have met with cases of it would furnish you with a brief record of their experience, a valuable mass of evidence would be obtained respecting the question of that medicine originating it or otherwise. Does it not sometimes happen where no mercury has been given? Does it not, moreover, now and then occur at such a length of time after the exhibition or this remedy that its causation cannot satisfactorily be traced to its operation? Again; does it not differ, greatly and palpably, from any affection known to depend on mercury? Some acute observations by Dl. Marshall Hall will be found upon the latter query in the debate alluded to. It is plain enough that where it does ensue after mercurial treatment, it does not follow that it takes place because of it; there may be a coincidence and nothing more. Both in a scientific and a jurisprudential point of view this inquiry is of deep interest. There is one fact which tends to render it very improbable that mercury produces this disease. How commonly is this remedy prescribed! what an every-day occurrence is salivation! and yet this affection is a rare one! There are numerous practitioners of great experience who are not cognisant of it. And why should it attack children rather than adults, when the former, comparatively speaking, bear the action of mercury better than the latter, if this medicine be the cause of it? If it does ever so influence the system, there surely must be some strange predisposition or idiosyncrasy present to account for its effects.

The first case which I ever witnessed of this affection was that of a little child ad- 
mitted into St. Bartholomew's Hospital it, whilst it progressed transversely from a under the care of Mr. Lawrence, and al- line drawn vertically through the centre of though it had the advantage of the judicious the lips to the left ear. Nor did it spare the treatment of that celebrated surgeon, the re- deeper parts; the frontal bone was partially sult was fatal. The disease had very pecu- exposed; the upper and lower jaws were liar features; there seemed a death of the extensively laid bare, and denuded of their parts affected without much preceding in- periosteum, and several teeth fell from their flammatory disease; it was the exact converse of phlegmon in its character. This child had taken a few doses of chalk with mercury, but I think it far from certain that this is the reason why it was thus afflicted. The most ample and convincing evidence is required before we regard this medicine as the origin of cases of this description; yet some who have imbibed the vulgar prejudices against mercury, not limiting their objections to the abuse of it (though it is one of the foremost and best of onr remedies, and therefore to be protected against unmerited charges), unhesjtatingly adopt most absurd conclusions respecting its operation.

Permit me to add a brief sketch of an affection apparently analogons to cancrum oris, which I lately witnessed as a complication of variola. In the beginning of last February I was requested to visit a litlle boy, three years old, in whom the variolous eruption had first appeared twelve days previously. He had gone on favourably until four or five days before my visit, at which time his mother observed a swelling of the left cheek, and on looking into the mouth saw a black spot, which quickly grew larger. I remarked a dark and evidently gangrenous patch occupying the whole thickness of the cheek, of a circular form, and of the size of a half-crown; this was situated at the angle of the left side of the mouth, involved the upper and lower lips to the same degree, and the centre of the mortified spot might be considered the point which once formed their junction. There were fever, an extremely rapid pulse, which beat 160 , and a general appearance of languor and prostration; the bowels were re. gular, the intellect clear, the appetite good, and he swallowed any nourishment which was offered him with avidity. Beef-tea and port-wine were recommended to be taken in liberal quantities and at fiequent inter rals in order to sustain the system, which seemed needful bey ond all things. For awhile the disease seemed stationary, and hopes were entertained that it would stay its ravages; but after the lapse of a ferv days it progressed with alarming celerity; nitric acid was applied along the line of demarcation which separated the dead from the living parts, and nutriment and stimuli were perseveringly administered, but in vain; the mortification persisted and advanced upwards to the forehead and temple, attacking in its course the soft parts of the orbit, whilst it left the eye itself urtouched. At the same time it travelled downwards as far as the larynx, killing the integuments which cover sockets. The mortified parts exhaled an insufferably fetid odour, and here and there hung in shreds. When the gangrene had endured a month, the child sunk exhausted. During this period he was calm and patient, slept well, and was subdued in the most gradual manner by his disease. Some hours before he died there was considerable hæmorrhage from vessels interfered with by the destructive process, and this, doubtless, shocked and lowered him greatly.

My friend, Mr. Wyatt, who saw the patient with me several times, can truly affirm that the above picture is of a far fainter colour than the original, to the horrible aspect of which no expression can do justice.

The entire of the mercury taken by the child during the whole period of his illness was included in four grains of hydrarg. $c$. creti, administered on the first day of the eruption, so that an interval of twelve days elapsed between the time it was given and the appearance of the gangrene. I think, therefore, it cannot be pretended that this was the cause of it; and I believe that in most of those cases where gangrene of the mouth has been considered consequent on that medicine, that the locality of the malady, rather than its nuture, has led to an erroneous conclusion. I wish that I could have offered a more valuable contribution to the history of this affection, and am, Sir, your obedient servant,

\section{Oxford, April 10, 1843.}

$$
\text { W. F. Barlow. }
$$

P.S. It is more than probable that the variolous inflammation gave rise to the disease I have described, but to account for its extension through parts which seemed to have recorered from the effects of the eruption is a matter of greater dificulty. But there was evidently a typhoid condition. which favoured both its occurrence and its spreading.

\section{ASCITES IN AN INFANT, SUCCESS. FULLY TREATED BY TAPPING.}

AT a late meeting of the Westminster Medical Society, Dr. CHow Ne related the following case:-

A child, E. —_, from her birth delicate, and liable to a disordered state of the bowels, having sometimes too much bile and sometimes too little; complexion fair; hair and eyes light; not subject to glandular enlargements. She had (owing to a series of events which made changes expedient) fieur nurses in succession :- 